\title{
OBSTRUÇÃO DAS ARTÉRIAS CARÓTIDAS E DAS PRINCIPAIS ARTÉRIAS CEREBRAIS
}

\author{
JosÉ ZACLIS * \\ O. RICIARDI CRUZ** \\ Gilberto G. M. AlmeidA ***
}

A oclusão da carótida por um trombo era tida até há pouco tempo como rara, constituindo sempre achado de necrópsia. Verneuil em 1872 e, ulteriormente Chiari e Ramsay Hunt, citados por Isch ${ }^{6}$, foram os primeiros a procurar a correlação entre a sintomatologia clínica de seus pacientes e a oclusão carotídea verificada ao exame necroscópico. Mais tarde, com o desenvolvimento e divulgação da angiografia cerebral, o diagnóstico de trombose da carótida primitiva e seus ramos bem como de artérias cerebrais tornou-se possível em vida. Após os primeiros casos, descritos por Sjöqvist ${ }^{13}$ e por Moniz ${ }^{10}$ o número de casos registrados na literatura mundial tem aumentado progressivamente. Em 1951, Johnson e Walker ${ }^{5}$ fazendo revisão da literatura coletaram 107 casos; três anos depois, Pallais e Bonnal 11 reuniram 170 casos; na revisão feita por nós incluindo as publicações até maio de 1955, o número de casos já era o dôbro daquele verificado um ano antes. Em quase todos os trabalhos relativos à trombose das carótidas ou das principais artérias cerebrais os autores se preocupam com o estudo das relações anátomo-clínicas, da etiopatogenia e dos aspectos angiográficos.

As manifestações clinicas das oclusões carotídeas são extremamente variáveis, podendo a afecção evoluir inteiramente assintomática. $\mathrm{Na}$ maioria das vêzes, entretanto, a oclusão carotidea determina hemiplegia ou hemiparesia, em geral desproporcionada, com predomínio do componente cefalobraquial. A hemiplegia pode ou não ser precedida de cefaléia em crises, acompanhada de alterações visuais e, raras vêzes, de vômitos e papiledema; nestas circunstâncias, em que há sinais de hipertensão intracraniana, torna-se necessário o diagnóstico diferencial com os processos expansivos intracranianos. As paralisias podem ser de instalação brusca, em forma de icto, ou de evolução progressiva. Freqüentemente são referidos casos que evoluem em surtos; hemiplegias ou hemiparesias transitórias, acompanhadas ou não de afasia, separadas por intervalos assintomáticos. Distúrbios da sensibilidade são menos freqüentes; quando presentes são, em geral, associados a disbúrbios motores. No exame clínico merece especial atenção a palpação das caróti-

* Trabalho do Serviço de Neurologia da Fac. Med. da Univ. de São Paulo (Prof. Adherbal Tolosa). Apresentado ao Departamento de Neuro-Psiquiatria da Associação Paulista de Medicina em 5 março 1956.

* Neurorradiologista; ** Plantonista de Neurocirurgia; *** Médico interno. 
das. Embora não se trate de elemento de valor absoluto, a palpação cuidadosa da região pode revelar um cordão duro que não pulsa. Os distúrbios psíquicos são freqüentes, superpondo-se, em certos casos, ao quadro da síndrome de Korsakoff, como observou Sorgo ${ }^{14}$. A afasia é usualmente encontrada nas oclusōes da carótida esquerda. Dos pares cranianos o nervo óptico é o mais freqüentemente atingido (edema de papila, amaurose, hemianopsia e outros distúrbios visuais); também pode ocorrer atrofia primitiva da papila quando a artéria oftálmica é ocluída. Outros pares cranianos podem excepcionalmente estar alteracos.

A oclusão trombótica da carótida é mais freqüente no homem do que na mulher; Moniz ${ }^{10}$ ao descrever a nova entidade nosológica apresentou 4 pacientes do sexo masculino; Elvidge e Werner ${ }^{2}$ dão a relação de $2: 1$ com predominância do sexo masculino; no mesmo sentido, Fisher ${ }^{3}$ observou relação de $8: 1$ em seus casos. Quanto à idade, as oclusões arteriais ocorrem de preferência entre a terceira e sexta décadas da vida, sendo raros os casos relatados fora dêsses limites; ímpar é o caso relatado por Clark e Linell ${ }^{1}$ com oclusão pré-natal da carótida interna. Predomina, na quase totalidade das publicaçōes, a oclusão da artéria carótida esquerda na proporção de $3: 2$, o que tem sido atribuído às diferenças anatômicas na distribuição arterial entre um e outro lado; porém, Hall e col.4, mediante estudos experimentais e necroscópicos, chegaram à conclusão de que não há preferência pelas artérias dêste ou daquele lado quanto à ocorrência dos fenômenos trombo-embólicos.

Dos exames subsidiários o líqüido cefalorraquiano pode apresentar-se normal, ou com alterações dos niveis tensionais, associadas ou não a hipercitose que em alguns casos é provocada pelo agente etiológico do processo (oclusões sépticas) e não pela oclusão arterial em si. $O$ exame eletrencefalográfico pode mostrar diminuição da atividade elétrica no hemisfério isquemiado (ondas lentas irregulares ou ritmo \& polimorfo). A pneumencefalografia não fornece, em geral, elementos ponderáveis para o diagnóstico, mostrando, quando muito, sinais de atrofia do hemisfério cerebral correspondente. Outros exames de laboratório só contribucm para o diagnóstico etiológico do processc.

O diagnóstico positivo da afecção é obtido pela angiografia, método que, além de mostrar a existência de bloqueio vascular, fornece a localização exata do trombo, o que pode ser de grande valor prático. Não obstante, invocando perigos que podem decorrer da injeção de contraste em artérias com paredes alteradas, alguns autores têm proposto outros métodos, clínicos ou instrumentais, para substituir a angiografia no diagnóstico das oclusōes arteriais. Assim Macchi e Carreras ${ }^{8}$ fazem o estudo eletrencefalográfico após a oclusão do lado oposto ao hemisfério comprometido; Sweet e col.15 utilizam o eletromanômetro para a medida da pressão intracarotidea; Pavia ${ }^{12}$ recomenda a tonoscopia; Maleci e Montanari" estudam as modificações eletrencefalográficas. Esses métodos, entretanto, são, em geral, indiretos, revelando, quando muito, conseqüências da oclusão arterial e não o processo oclusivo em sua sede exata, razão pela qual a angiografia carotídea consti- 

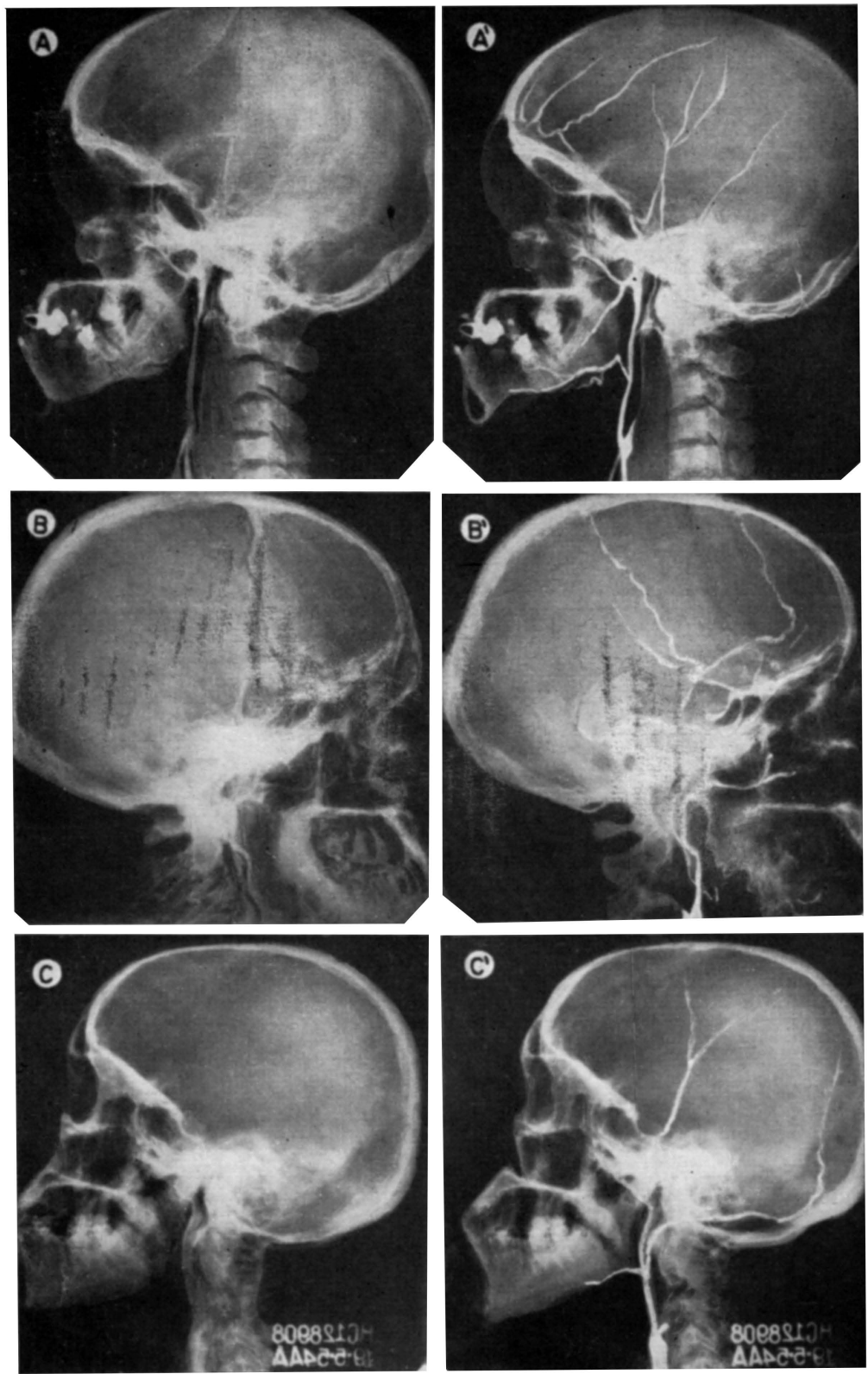

Fig. 1 - Diferentes formas de "côto" do segmento visivel da artéria carótida interna em casos de trombose; em $\mathrm{A}$, côto em forma de funil; em $B$, côto em forma de bisel; em $C$, ausência de côto: artéria carótida interna bloqueada em sua origem. 
tui, a nosso ver, o método de escolha para o diagnóstico das oclusōes arteriais no segmento cefálico.

Várias são as causas de oclusão da artéria carótida e de seus ramos. A maioria dos autores refere como principal causa a arteriosclerose e, em ordem decrescente, a lues, a trombangeite obliterante, a periarterite nodosa, as malformações arteriais e anomalias congênitas do polígono de Willis. A
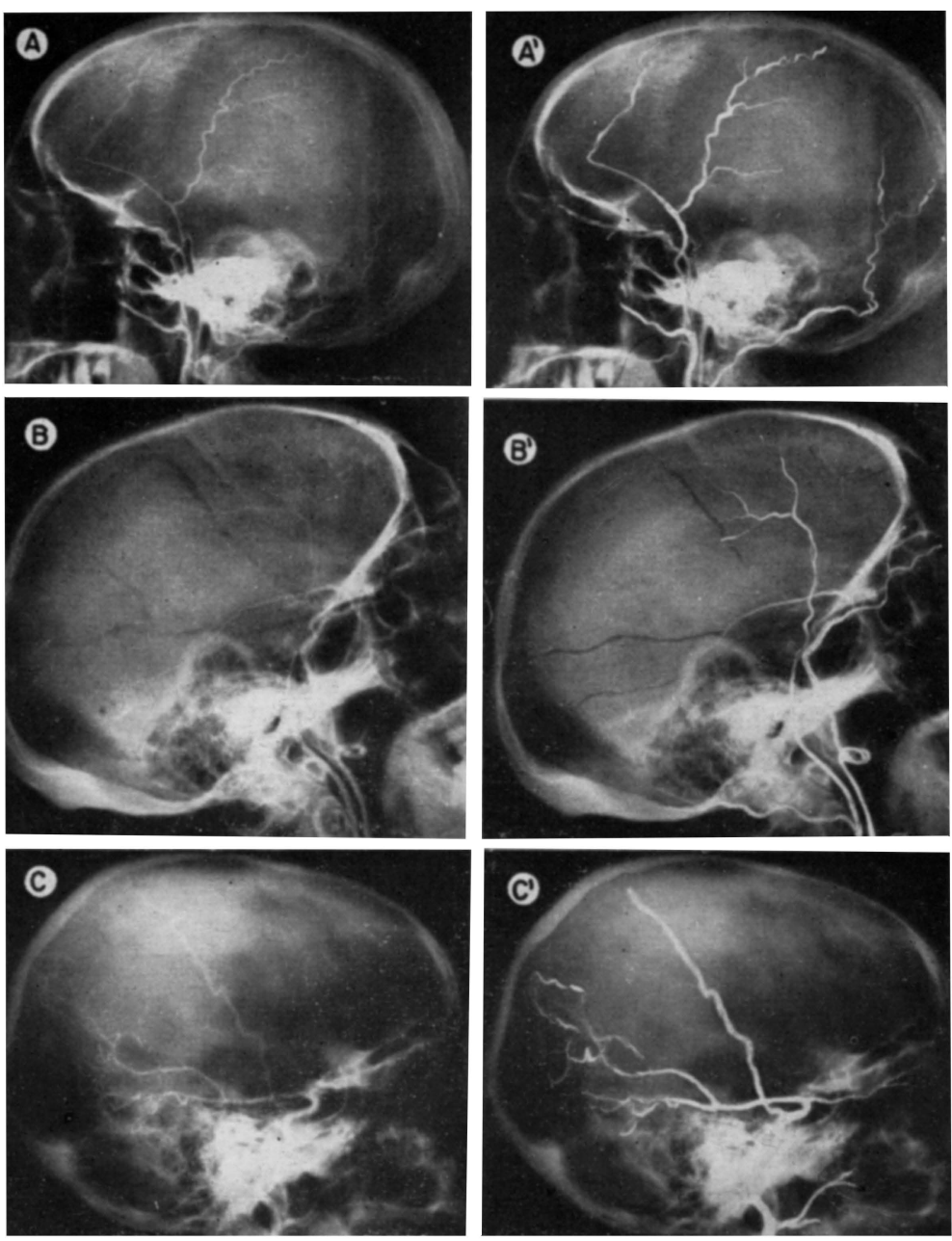

Fig. 2 - Oclusão do segmento intracraniano (sifão) da carótida interna; em A e B, oclusão acima da emergência da artéria oftálmica; em $C$, oclusão da carótida interna acima da emergência do ramo comunicante posterior, aparecendo, em conseqüencia, as imagens da artéria cerebral posterior e da oftálmica. 
endocardite bacteriana, observada por Herweg ‘, e processos sépticos são causas menos freqüentes. Os traumatismos crânio-encefálicos e cervicais, assim como as compressões extrínsecas dos vasos do pescoço exercidas por tumores vizinhos, são causas indiscutíveis de oclusão carotidea. Os espasmos constituem causa transitória que ocorre com alguma freqüência durante as angiografias, principalmente em artérias cerebrais.
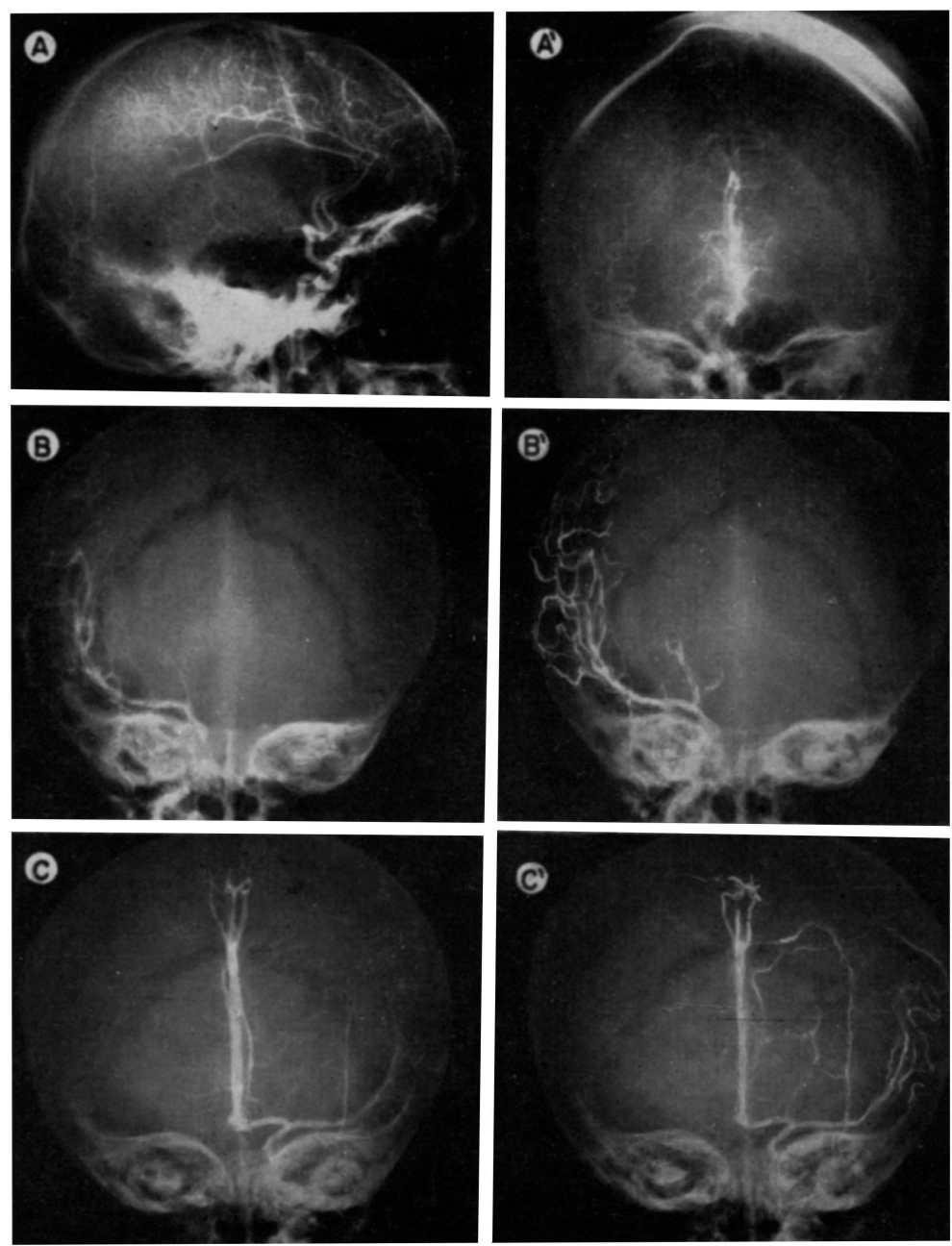

Fig. 3 - Oclusão de artérias cerebrais; em A e A', incidencia lateral e sagital mostrando ausência da imagem da artéria cerebral média; em $B$, ausência da imagem da artéria cerebral anterior do lado direito ocluída em sua origem; em $\mathrm{C}$, angiografia controlateral mostrando os ramos da carótida esquerda e o segmento pós-comunicante da artéria cerebral anterior direita. 


\section{MATERIAL E MÉTODO}

Nosso material consta de 23 casos de oclusão completa da artéria carótida primitiva ou de seus ramos. Esse número representa aproximadamente 3,3\% do total dos casos submetidos a angiografias cerebrais na Clínica Neurológica do Hospital das Clinicas da Fac. Med. da Univ. de São Paulo. Assim como a maioria dos autores, encontramos também franco predominio da carótida interna com sede preferencial de trombose: dos 23 casos de oclusão arterial completa, 16 se referiam à carótida interna, 2 à carótida primitiva e 5 a artérias cerebrais. Em três dêstes últimos a oclusāo foi observada no segmento inicial $\left(M_{1}\right)$ da artéria cerebral média e, em dois, no segmento horizontal $\left(A_{1}\right)$ da cerebral anterior (fig. 3 ); convém assinalar que, nestes dois casos, não temos elementos para excluir a hipótese de se tratar de agenesia dêsse segmento da artéria cerebral anterior. Dos 16 vasos de oclusão da carótida interna o processo estava localizado na origem do vaso em 11, e no segmento intracraniano em 4 (fig. 2); no caso restante a oclusão situava-se $5 \mathrm{~cm}$ acima da origem da artéria.

Empregamos como rotina a angiografia cerebral pela técnica percutânea, puncionando a carótida primitiva, utilizando como contraste o Cilatrast a $30 \%$ ou o Nosilan a $35 \%$, na dose de $15 \mathrm{ml}$ para cada injeção. Quando o caso exigia, o paciente era submetido à anestesia geral pelo Thio-Nembutal ou Surital, associado à succinilcolina (Celocurin) por via venosa. Cada série de radiografias compreendia duas exposições em incidência sagital e duas ou três em incidência lateral. Para maior segurança no diagnóstico em 11 casos o exame foi repetido, na mesma sessão ou após um período que variou de 5 a 30 dias. A angiografia controlateral, feita em 12 casos, além de fornecer a confirmação do bloqueio vascular, permitiu o estudo da circulação de suplência.

Nos dois casos de oclusão da carótida primitiva o aspecto angiográfico não pôde ser demonstrado; em ambos palpava-se a artéria como cordão duro, não pulsátil, cuja punçāo resultou negativa. Em todos os outros casos foi possivel demonstrar a extremidade proximal e as caracteristicas morfológicas do segmento arterial ocluido.

\section{RESULTADOS}

Analisando o quadro 1 verifica-se que a idade dos pacientes variou entre 10 meses (um ano) e 56 anos (dois casos); a idade dos demais pacientes oscilava entre 30 e 50 anos. A predominância do sexo masculino foi por nós observado na proporção de $4: 1$, próxima portanto da relação de Eldvidge e Werner ${ }^{2}$, referida também por outros autores.

\begin{tabular}{|c|c|c|c|c|c|c|c|c|}
\hline No & Registro & Sexo & Idade & No & Registro & Sexo & & dade \\
\hline 1 & 394897 & $\sigma$ & 23 & 12 & 256465 & 우 & & 37 \\
\hline 2 & 367917 & $\sigma^{\circ}$ & 27 & 13 & 406544 & $\sigma$ & & 41 \\
\hline 3 & 348325 & $\sigma^{\pi}$ & 33 & 14 & 413551 & $\sigma^{*}$ & & 45 \\
\hline 4 & 360725 & $q$ & 25 & 15 & 394044 & $\sigma^{\pi}$ & & 30 \\
\hline 5 & 345517 & $\sigma$ & 37 & 16 & 267744 & 우 & & 38 \\
\hline 6 & 257782 & $0^{*}$ & 23 & 17 & 359577 & 8 & & 23 \\
\hline 7 & 391618 & $\sigma$ & 24 & 18 & 325053 & $\delta$ & & 56 \\
\hline 8 & 273847 & $\sigma^{*}$ & 40 & 19 & 307771 & $\sigma$ & & 23 \\
\hline 9 & 353050 & 운 & 26 & 20 & 374738 & $\sigma^{*}$ & & 35 \\
\hline 10 & 384781 & $\sigma^{x}$ & 31 & 21 & 408296 & $\sigma$ & & 56 \\
\hline \multirow[t]{2}{*}{11} & 382418 & $0^{x}$ & 25 & 22 & 388976 & $\sigma$ & 10 & meses \\
\hline & & & & 23 & 192332 & $\sigma^{\pi}$ & & 34 \\
\hline
\end{tabular}

Quadro 1 - Distribuição dos pacientes segundo idade e sexo. 


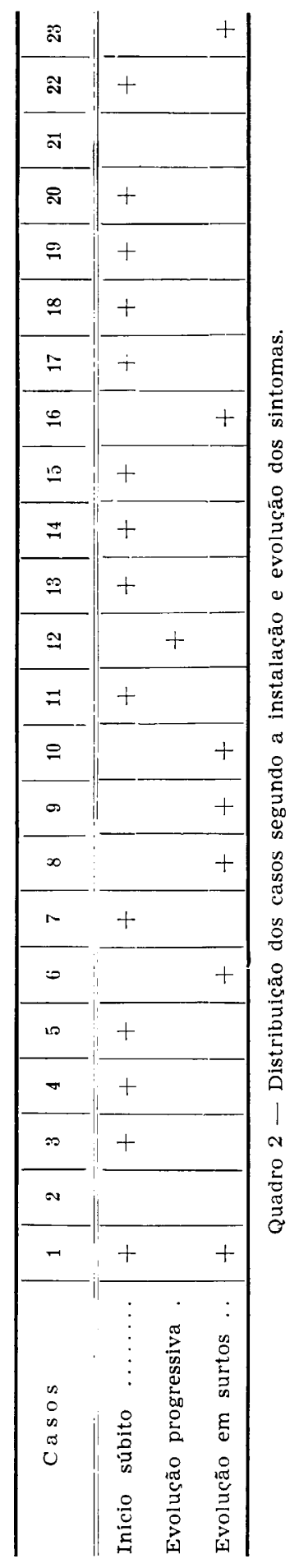

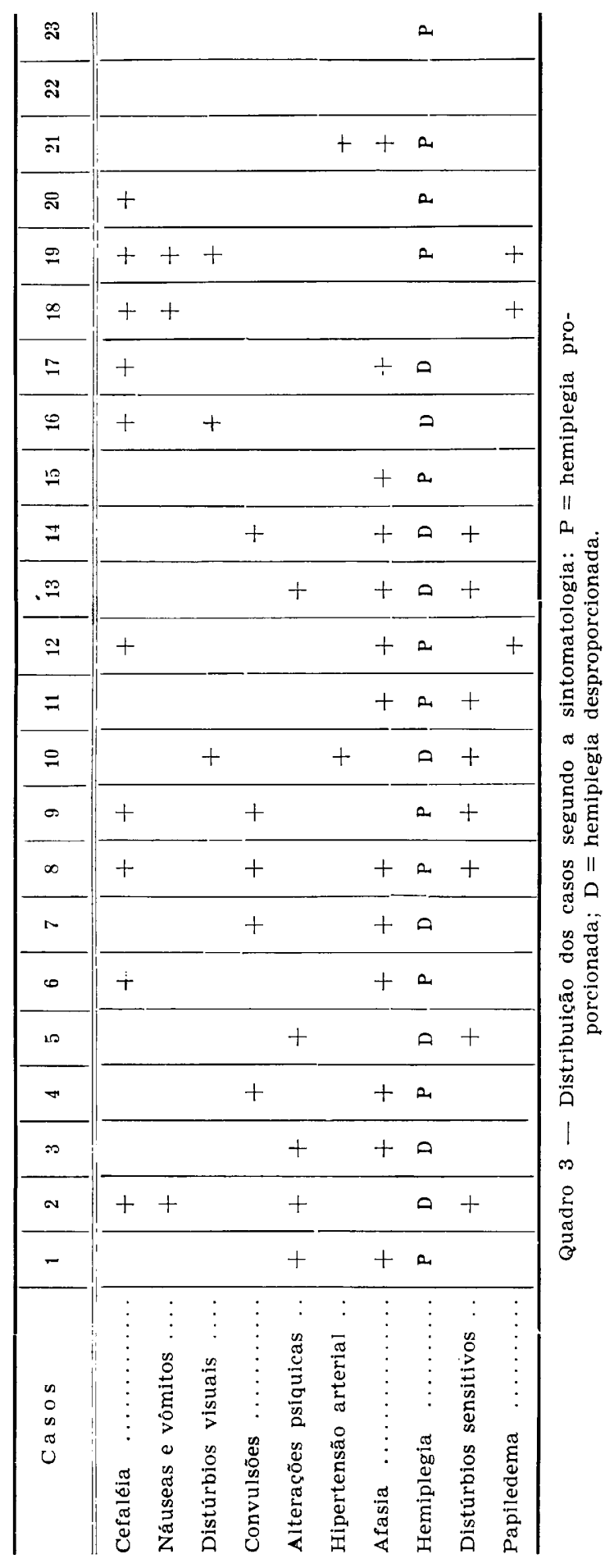


Quanto ao quadro clínico verificamos (quadro 2) que o início da moléstia foi brusco em 13 casos; em 8 observamos surtos em número de 2 a 5 , com remissão total dos sintomas nos intervalos; sòmente em um caso a evolução foi lentamente progressiva (cefaléia, alterações motoras, afasia transitória).

No quadro 3 verifica-se que a cefaléia foi encontrada em 10 casos, em geral como sintoma prodrômico: em dois dêsses casos a cefaléia era associada a vômitos e perturbações visuais; em um caso a diminuição da acuidade visual foi o único sinal prodrômico. Cinco pacientes apresentavam convulsões; em um caso generalizadas e nos 4 restantes, do tipo jacksoniano. O exame físico geral não fornece elementos ponderáveis para o diagnóstico das oclusões arteriais do segmento cervicocefálico; não obstante a palpação das regiões carótidas foi decisiva em dois casos de oclusão da artéria carótida primitiva (casos 1 e 2), permitindo perceber um cordão duro não pulsátil; no tocante às oclusões mais altas e, particularmente, aos casos de oclusão de vasos intracranianos, o valor da palpação é diminuto. Afasia foi encontrada em todos os casos de oclusão da carótida esquerda; encontramos também afasia em um paciente dextro, portador de oclusão da artéria carótida direita. Distúrbios psíquicos diversos foram assinalados em 5 pacientes. Hemiplegia foi a manifestação predominante nas diferentes variedades topográficas de oclusão arterial; ẹm 12 pacientes era proporcionada e em 9 havia franco predomínio cefalobraquial. Em um paciente (caso 22) foi observada tetraparesia, a qual, evidentemente, não pode ser explicada pela oclusão arterial unilateral. Apenas um paciente (caso 18) não apresentava alterações motoras. Distúrbios da sensibilidade superficial e profunda foram encontrados em 8 casos; nos restantes a pesquisa era prejudicada quer pela afasia quer pela falta de cooperação dos pacientes. Dos nervos cranianos encontramos alterações apenas para o lado do óptico; o fundo de ôlho, examinado em 13 pacientes, mostrou-se alterado em 4; em 3 tratava-se de franco edema de papila, em um dêles associado a cefaléia, vômitos e hipertensão liquórica.

No quadro 4 observa-se que o liqüido cefalorraquiano foi normal em 16 casos; em 6 revelou alterações (hipertensão isolada ou associada a hipercitose com predomínio linfoplasmocitário). O EEG, realizado em 8 casos, revelou, em 6, diminuição de atividade elétrica no hemisfério isquemiado, com desorganização do ritmo $\alpha$ em um dêles; em 2 pacientes o exame resultou normal. A pneumencefalografia, feita em 4 pacientes, mostrou quadro sugestivo de dilatação ex-vacuo do ventrículo lateral correspondente ao hemisfério isquemiado em 3 ; no caso restante êsse exame foi normal.

Quanto à sede da oclusão o quadro 5 mostra predomínio da carótida interna (16:23), sendo 11 casos de oclusão à esquerda e 5 à direita; dêstes 16 casos, em 4 a obstrução situava-se no segmento intracraniano da artéria e, nos 12 restantes, ao nível do segmento cervical. Nos 7 outros casos, a sede da obstrução era a seguinte: um na carótida primitiva direita, um na carótida primitiva esquerda, um na artéria cerebral anterior direita, um na cerebral anterior esquerda e três na artéria cerebral média (dois à direita e um à esquerda). 


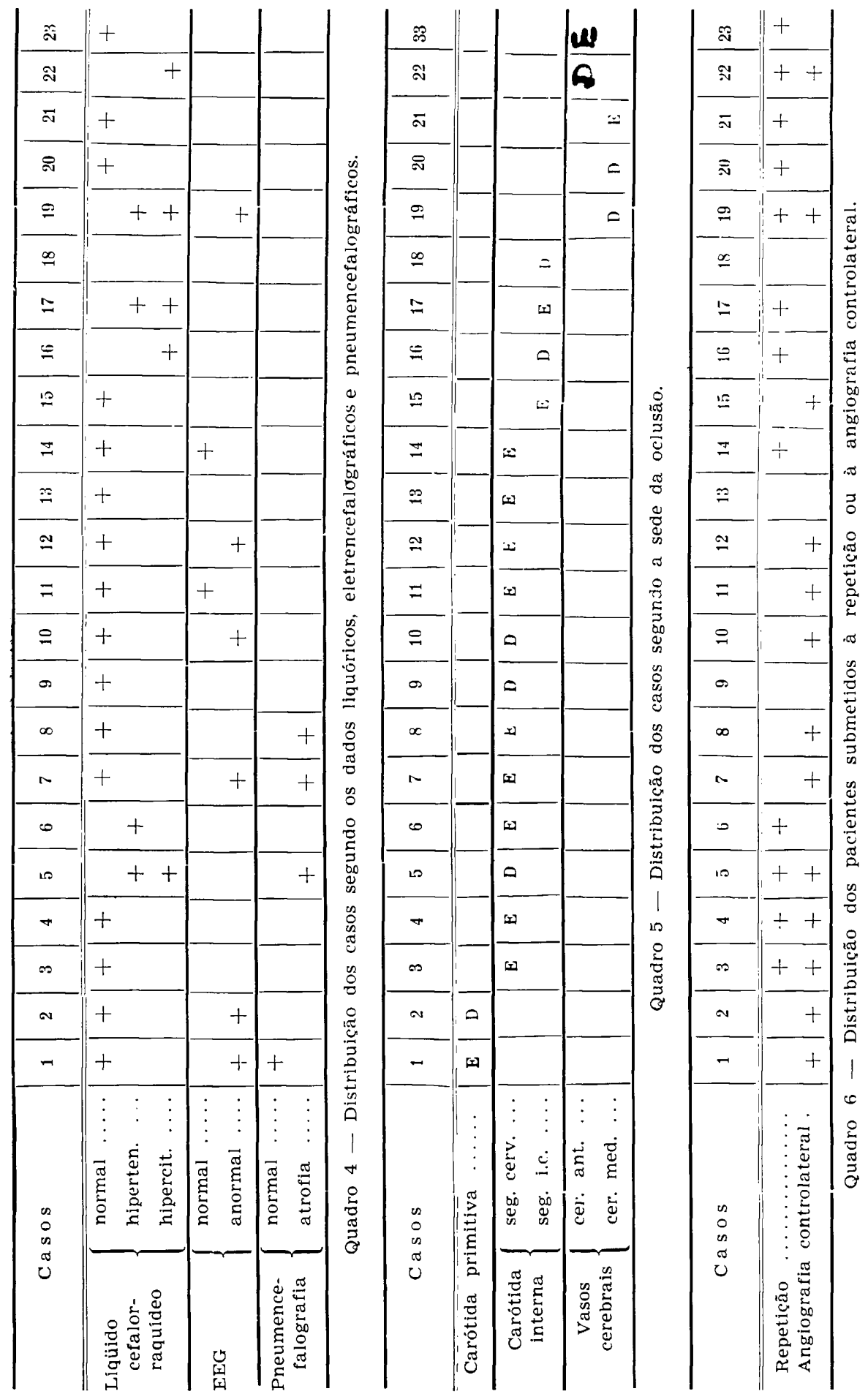



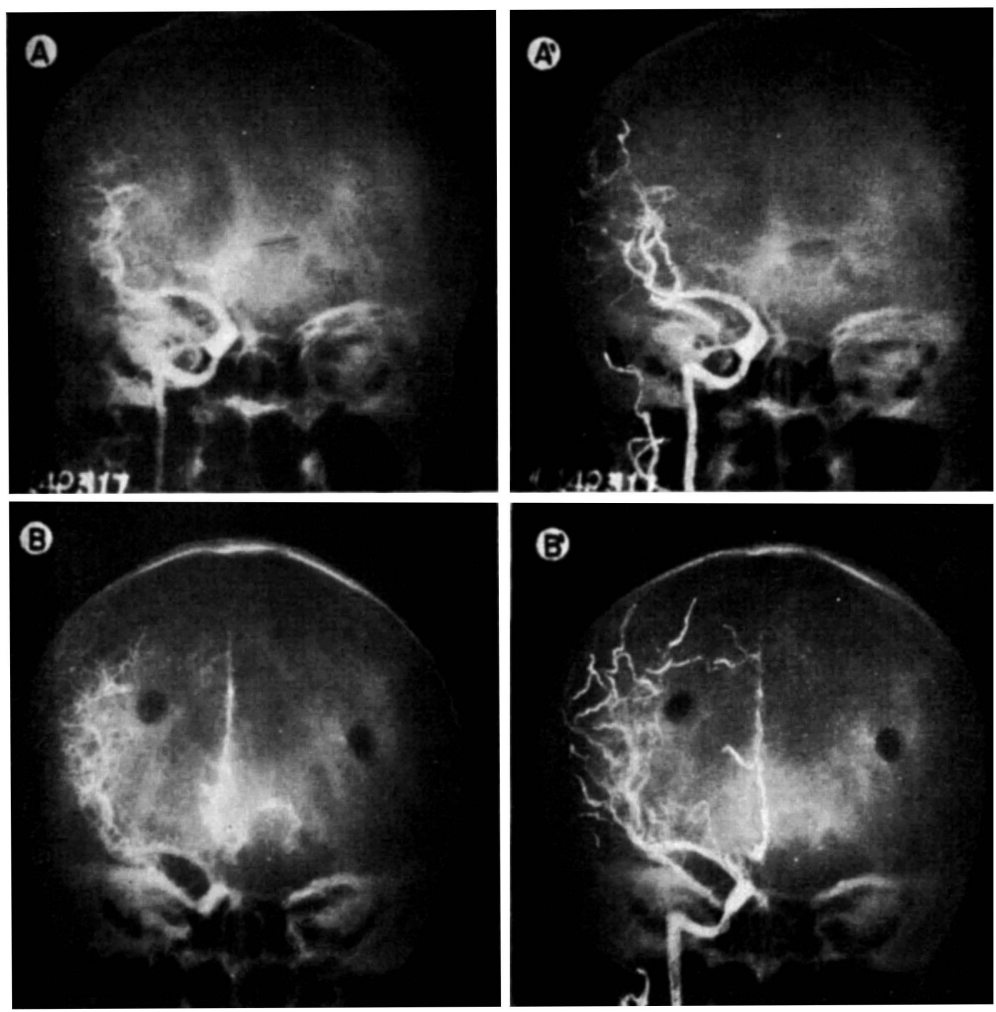

Fig. 4 - Oclusão transitória (espasmo) da artéria cerebral anterior; em A, ausência da imagem da artéria cerebral anterior; em B, angiografia do mesmo lado, 5 meses depois, mostrando a contrastação dessa artéria.

A angiografia cerebral via artéria carótida primitiva é o exame de escolha para o diagnóstico das oclusões arteriais cervicais e encefálicas. Do ponto de vista angiográfico a oclusão de uma artéria é caracterizada, em sintese, pela interrupção brusca da imagem arterial. Nos casos em que o processo atinge a carótida interna a radiografia mostra, em geral, um segmento da carótida primitiva, a carótida externa e seus ramos e um pequeno côto da carótida interna, de forma variável; não aparecem os vasos cerebrais, vendo-se, projetado sôbre a imagem do crânio os ramos epicranianos e meníngeos da carótida externa. Dada a possibilidade de oclusão arterial transitória em conseqüência de espasmo (fig. 4), o diagnóstico de obstrução em nossos casos foi baseado, sempre que possivel (quadro 6), na obtenção da mesma imagem em exames repetidos (casos $3,4,5,6,14,16,17,19,20$, 21, 22 e 23), e no enchimento dos vasos cerebrais do lado da oclusão pelo contraste injetado na carótida do lado oposto $(\operatorname{casos} 1,2,3,4,5,7,8,10$, 11, 12, 15 e 22). Em 5 casos a repetição foi dispensada dado o aspecto ca- 
racterístico do côto do segmento visivel da artéria ocluída (fig. 1). Também não foram submetidos a nova angiografia um caso (caso 13) confirmado pela biópsia, dois verificados em autópsia (casos 4 e 18); em outros dois (casos 1 e 12), cujo diagnóstico fôra feito pela palpação e pela contraprova da angiografia controlateral, também não houve, como é óbvio, repetição do exame, pois tratava-se de oclusão da artéria carótida primitiva.

No que se refere à etiopatogenia, em três casos $(8,19$ e 21) os exames subsidiários revelaram tratar-se de pacientes luéticos; em dois casos (4 e 10) a trombose foi atribuida, com base no exame clínico, à arteriosclerose, o que foi confirmado em um dêles (caso 4) pelo exame necroscópico; em dois casos (5 e 12) havia antecedentes de trauma crânio-encefálico; dois pacientes (casos 7 e 14) eram portadores de moléstia de Chagas; finalmente, em um caso (18) o exame necroscópico revelou malformação angiomatosa que atingia todo o polígono de Willis. Nos restantes casos não foi obtido qualquer indício relativo à etiopatogenia. Dois casos de trombose arterial (casos $9 \mathrm{e}$ 12) foram observados em pacientes que, submetidos anteriormente à angiografia cerebral, apresentaram os vasos de aspecto normal; nestes casos, embora sem provas cabais, julgamos razoável relacionar a trombose ao trauma arterial produzido pela agulha por ocasião da primeira angiografia.
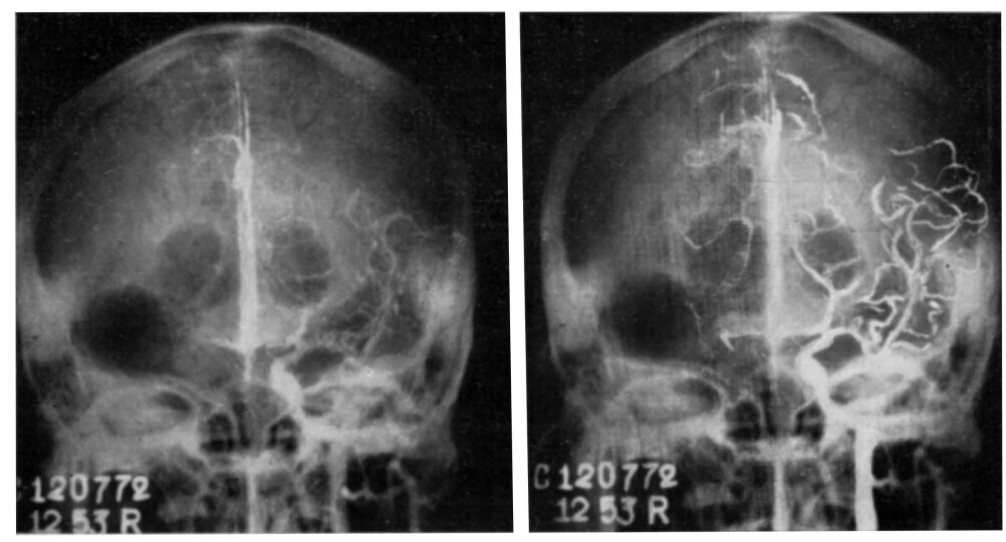

Fig. 5 - Angiografia controlateral mostrando passagem, para artéria cerebral anterior, de contraste injetado na carótida do lado săo.

Ao encerrar êste relato sintético de nossos casos de obstrução arterial, desejamos salientar que em nenhum paciente se observou quaisquer acidentes durante ou após o exame. A angiografia controlateral, além de constituir contraprova da oclusão vascular, serve ainda para demonstrar as vias de suplência circulatória. Em todos os nossos casos submetidos à angiografia controlateral observou-se que os vasos cerebrais correspondentes à carótida ocluída, recebiam sangue proveniente da carótida do lado oposto através 
do ramo comunicante anterior (fig. 5). Em um só caso, de oclusão da carótida interna (caso 7), observou-se claramente a imagem da artéria oftálmica, demonstrando a anastomose dêsse vaso com ramos da carótida externa.

\section{RESUMO}

São reunidos os dados relativos a 23 casos de obstrução de artérias crânio-encefálicas: carótida primitiva em 2 casos; carótida interna em 16 casos; artéria cerebral em 2; cerebral média em 3. São analisados a incidência da obstrução arterial em relação à idade e ao sexo, sua sintomatologia e os métodos de diagnóstico. Foi observada nítida predileção para o sexo masculino. As idades extremas dos pacientes foram de 10 meses e de 56 anos, variando os restantes entre 20 e 50 anos. Quanto às manifestações clínicas destaca-se a hemiplegia, que ocorreu em 21 dos pacientes. No tocante ao diagnóstico angiográfico, os autores são de opinião que, para afastar a possibilidade de oclusão transitória devida a espasmo, é importante que o mesmo aspecto seja verificado em exames sucessivos, principalmente quando o segmento visível da artéria ocluida não apresentar deformação característica. Como contraprova foi feita, em 12 casos, a angiografia controlateral; em nenhum dêstes casos houve qualquer acidente atribuivel ao exame. $\mathrm{A}$ angiografia controlateral, além de constituir contraprova da oclusăo vascular, permite o estudo da circulação de suplência.

\section{SUMMARY}

Occlusion of the carotid arteries and the main cerebral arteries.

This paper concerns 23 cases of arterial occlusion. The affected artery were primitive carotid ( 2 cases), internal carotid (16), anterior cerebral artery (2), the Sylvian artery (3). Frequency of the arterial occlusion related to age and sex, symptomatology and diagnostic methods are studied. A marked dominance in male patients was found. The extremes of age in the patients examined were 10 months and 56 ycars; the other patients had ages between 20 and 50 years. Hemiplegia was the most frequent symptom (21 patients). The authors are convinced that, to discard the cases of transitory occlusion due to spasm, it is necessary to visualize the same aspect in subsequent examinations, mainly when the visible section of the occluded artery does not show any characteristic deformity. In 12 cases, for checking purpose, angiography in the opposite side was performed; no accident occurred in these cases. The heterolateral angiography represents not only a cross-examination of vascular occlusion, but permits to study the compensatory circulation.

\section{BIBLIOGRAFIA}

1. CLARK, R. M.; LINELL, E. A. - Prenatal occlusion of the internal carotid artery. J. Neurol. Neurosurg. a. Psychiat. (London), 17:295 (novembro) 1954.2. ELVIDGE, A. R.; WERNER, A. - Hemiplegia and thrombosis of the internal carotid 
system. Arch. Neurol. a. Psychiat., 66:752 (dezembro) 1951. 3. FISHER, M. - Occlusion of the carotid arteries; further experiences. Arch. Neurol. a. Psychiat., 187204, 72:7 (agôsto) 1954. 4. HALI, P.; DENCKER, S. J.; BIORCK, G. — Studies on the mitral stenosis. Observations on the incidence and distribution of cerebral emboli with regard to the possibilities of their prevention during operatives procedures. Am. Heart. J., 44:600 (outubro) 1952. 5. JOHNSON, H. C.; WALKER, A. E. - The angiographic diagnosis of spontaneous thrombosis of the internal and common carotid arteries. J. Neurosurg., 8:631 (junho) 1951. 6. ISCH, F. - Essai clinique sur l'hémiplegie par thrombose de la carotide interne ou de ses branches. These, Strasbourg, 1950. 7. HERWEG, J. - Tetralogy of Fallot and cerebral thrombosis. J. Pediat., 35:642 (novembro) 1949. 8. MACCHI, G.; CARRERAS, M. - Importanza delle modificazioni eletroencefalografiche ottenute mediante compressioni della carotide nella diagnostica della lesioni ostrutive del circolo carotideo. Valore della semiologia eletroencefalografica nelle trombosi carotide. Gior. di Psichiat. e Neuropatol., 82:518, 1954. 9. MALECI, O.; MONTANARI, M. - L'EEG nelle lesioni vascolare acute a focolaio dell'encefalo. Sist. Nerv. (Milano), 4:5 (setembro) 1951.10. MONIZ, E.; LIMA, A.; LACERDA, R. - Hémiplegies par thromboses de la carotide interne. Présse Méd., 47:977, 1937. 11. PALLAIS, J. E.; BONNAL, J. - Les thromboses spontanées de la carotide interne et de la carotide primitive. Sem. d. Hôp., 30:17 (março) 1954. 12. PAVIA, J. L. - Tonoscopía diferencial en las lesiones de la carotida interna. Rev. Otoneuroftalm. (Valencia), 12:407 (novembro) 1953. 13. SJÖQVIST, O. - Uber intrakranielle Aneurysmen der Arteria carotis and deren beziehung zur ophtalmoplegischen Migräne. Nervenartz, 9:233, 1936. 14. SORGO, W. - Über den durch gefässprozesse bedingten verschluss der Arteria carotis interna. Zentrbl. Neurol., 3, 1939. 15. SWEET, W. H.; SARNOFF, S. J.; BAKAY, Z. - A clinical recording internal carotid pressure; significance of change during carotid occlusion. Surg., Gynecol. a. Obst., 90:327 (março) 1950.

Clínica Neurológica. Hospital das Clinicas da Fac. Med. da Univ. de São PauloCaixa Postal 3461 - Sĭo Paulo, Brasil. 